\title{
Bridging gaps in health information systems: a case study from Somaliland, Somalia
}

Ahmed Askar, Malekafzali Ardakani ${ }^{2}$ and Reza Majdzade ${ }^{2}$

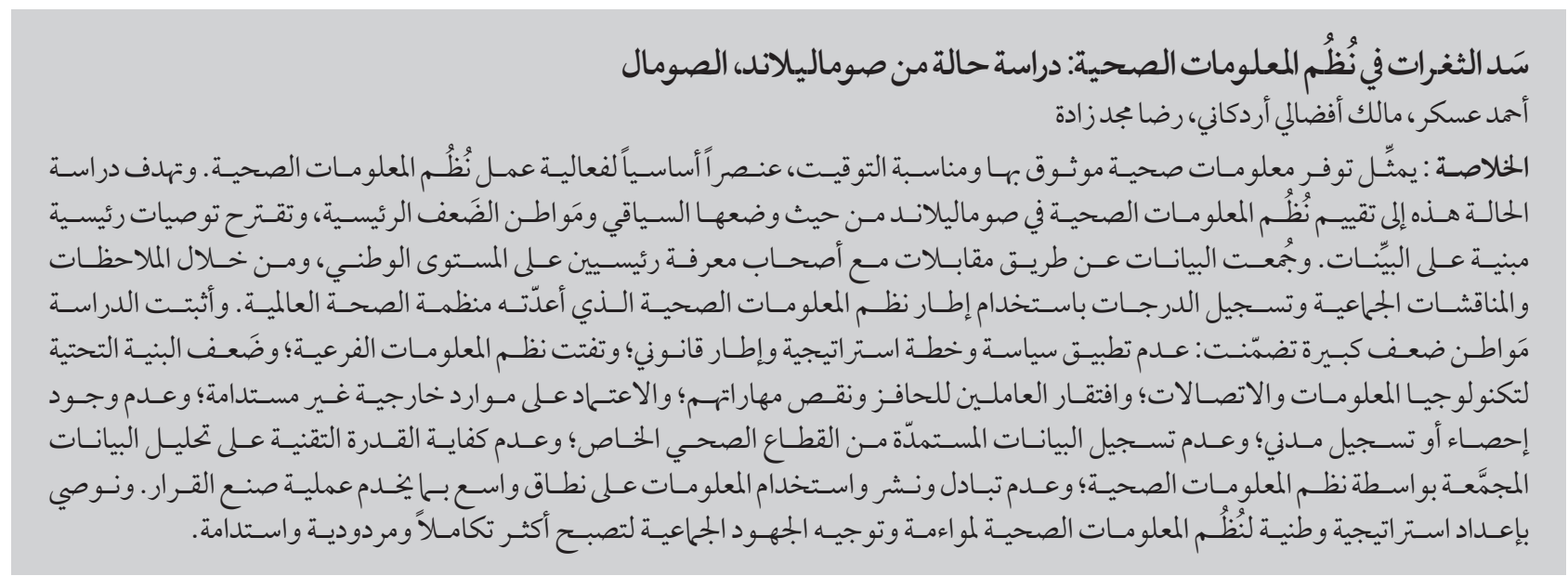

ABSTRACT Reliable and timely health information is fundamental for health information systems (HIS) to work effectively. This case study aims to assess Somaliland HIS in terms of its contextual situation, major weaknesses and proposes key evidence-based recommendations. Data were collected through national level key informants' interviews, observations, group discussion and scoring using the HIS framework and assessment tool developed by World Health Organization Health Metrics Network (WHO/HMN). The study found major weaknesses including: no policy, strategic plan and legal framework in place; fragmented sub-information systems; Poor information and communications technology (ICT) infrastructure; poorly motivated and under-skilled personnel; dependence on unsustainable external funds; no census or civil registration in place; data from private health sector not captured; insufficient technical capacity to analyse data collected by HIS; and information is not widely shared, disseminated or utilized for decision-making. We recommend developing a national HIS strategic plan that harmonizes and directs collective efforts to become a more integrated, cost-effective and sustainable HIS.

\section{Combler les lacunes des systèmes d'information sanitaire : étude de cas au Somaliland, Somalie}

RÉSUMÉ Une information sanitaire fiable et fournie en temps voulu est fondamentale pour assurer l'efficacité des systèmes d'information sanitaire. La présente étude de cas avait pour objectif d'évaluer les systèmes d'information sanitaire au Somaliland au vu de la situation contextuelle et des faiblesses majeures du pays, et propose également des recommandations essentielles reposant sur des bases factuelles. Les données ont été collectées au moyen d'entretiens auprès d'informateurs principaux au niveau national, ainsi que d'observations, de discussions de groupe et de systèmes de notation, en utilisant le cadre et l'outil d'évaluation pour les systèmes d'information sanitaire mis au point par le Réseau de Métrologie sanitaire de l'Organisation mondiale de la Santé (OMS/RMS). L'étude a révélé des faiblesses de taille incluant : I'absence de politique, de plan stratégique et de cadre juridique; la fragmentation des systèmes d'information secondaires; la faiblesse de l'infrastructure informatique; la faible motivation et la sousqualification des personnels; une dépendance aux fonds extérieurs non viables; l'absence de recensement et de systèmes d'enregistrement des faits d'état civil ; le non-recueil des données du secteur privé de la santé ; l'insuffisance des capacités techniques pour analyser les données collectées sur le système d'information sanitaire ; ainsi que l'insuffisance du partage, de la diffusion et de l'utilisation de l'information. Nous recommandons l'élaboration d'un plan stratégique national pour les systèmes d'information sanitaire (SIS) qui permette l'harmonisation et l'orientation des efforts collectifs en vue de de systèmes d'information sanitaire davantage intégrés, d'un bon rapport coût-efficacité et durables. 


\section{Introduction}

Reliable and timely health information is critical input for health systems to develop and perform at high level of effectiveness, efficiency and quality. For any country, well-processed, synthesized and presented health information is profoundly needed for making informed evidence-based decisions to improve population health. A comprehensive integrated system that provides such information is known as Health information Systems (HIS) (1), which aims to support the decision-making process with relevant evidence, and thus ultimately contributes to improve health status. More importantly, information could be described as "the guidance of health systems", since it is good information and evidence that leads to improved governance and stewardship; provision of quality health care services; and more efficient management of resources (money, manpower, drugs, supplies and technology) $(2,3)$.

Health information systems generate data from various sources including health facility data, administrative records, household surveys, censuses, vital registration, national health accounts and health research. There is no standard formula of data sources that should be applicable in every setting. As a principle, it is advisable to define - at the initial phase of setting up HIS - what data should be collected as "core health indicators" with their appropriate and cost-effective system of data collection and reporting. This step has not been always straightforward in many countries (4). For example, the HIS in low-income countries has long been under-developed and poorly performing (5). Similarly, in resourcesconstrained settings, it has been widely recognized that poor availability and quality of information hinders formulation of health policies and plans, design and implementation of public health programmes, or allocation of resources. A review made of HIS implementation has shown challenges: 1) resource and infrastructure limitations; 2) poor information and communications technology (ICT) for health; 3) absence of enforced legal framework for information management; 4) limited use of common interoperability standards; 5) lack of an appropriately trained workforce; and 6) fragmented HIS sub-systems (6). Other similar research papers revealed the following: poor data quality; limited use of available information, weaknesses in data analyzing capacity, and poor HIS management practices $(7,8)$.

In striving to improve HIS, most countries in the Region have comprehensively reviewed and assessed their HIS with support of the World Health Organization (WHO) and the Health Metric Network (HMN). For example, Sudan's HIS assessment revealed that there are seven surveillance systems designed vertically with their own specific approach to data collection, analysis and information products. Therefore, Sudan realized the importance of an integration strategy as a key solution to better data production, use and dissemination (9-11).

In the case of Somaliland (an independent state that seceded from Somalia in 1991), the whole health system is functioning poorly. Health information is often limited due to convergence of multiple factors including: under-investment in information systems; absent of HIS strategy; extremely poor technical capacity for data collection, analysis, dissemination and use; inadequate staffing levels; and fragmentation in data collection, information production and dissemination (12). Consequently, ministry of health $(\mathrm{MoH})$ decision-makers and planners, health partners and donors often face a deficiency of timely and accurate information to determine a country's health status, set priorities, and assessment of public health programmes.

Currently there is no comprehensive HIS in place in Somaliland.
Nevertheless, there are vertical disease surveillance systems and a national level Health Management Information System (HMIS), which operates as section in the $\mathrm{MoH}$ directorate of planning, policy and strategic information. The HMIS was first established in 1995 as a small pilot project in Morodi-jeh region with a support of WHO. Few hospitals and MCHs Maternal and child health centers were selected to report to HMIS, and staff used to compile data in a very simple national excel sheets. Although this basic HMIS was very limited in terms of geographic scope and data sources, it provided good insights into vaccine coverage, trends in epidemic prone diseases and outbreaks. In 2009 the HMIS was expanded with support of the Global Fund to Fight AIDS, Tuberculosis and Malaria (GFATM) and managed by the United Nations Children's Fund (UNICEF) (13).

The National Health Sector Strategic Plan (HSSP) 2013-2016 aims at "improving HMIS to increase the availability, quality, value and use of information for decision-making, planning and policy formulation". This has been driven by increasing concerns shown by various health sector stakeholders and development partners to strengthen and reform health information systems (14). The need to guide such efforts using research evidence was crucial and was motivated by large data gaps in availability, access and utilization of reliable health information, as a result of fragmented, under-developed and poor-performing HIS. More specifically, the strategic plan aimed to describe the contextual framework in which HIS operates, identify major gaps and their determinists, and to propose evidencebased recommendations for action.

\section{Methods}

The study began in early October 2013 and finalized by end of June 2014. The scope of the studyis to assess Somaliland 


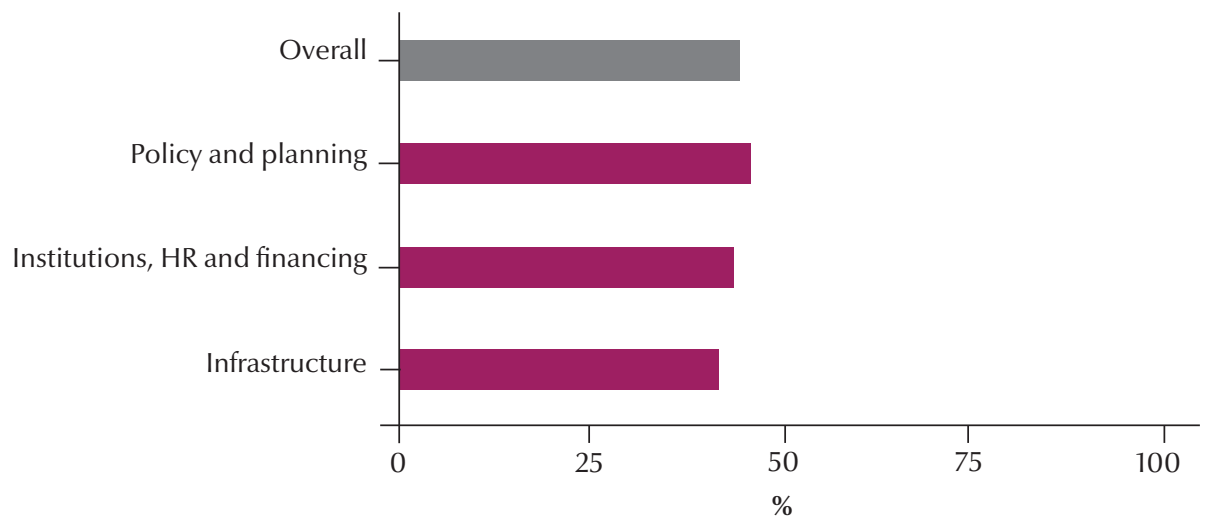

Figure 1 Par chart display of results of HMIS resource component

HMIS as comprehensively and systematically as possible, and thus studies all six main components of health HIS as described in HMN framework (15). A written research proposal highlighting the significant of study outcomes for improving HMIS was communicated with $\mathrm{MoH}$ concerned departments, which resulted in official ethical approval and support. A small team was subsequently trained and oriented to facilitate data collection processes, which proceeded in three sequence phases:

\section{Desk and documentries review}

Secondary data were collected from HMIS documents and partners. Such documents included: national health policies (NHP11) and health sector strategic plan (HSSP 2013-2016);
HMIS section documentaions; monitoring and evaluation reports; surveys reports; disease surveillance system reports; HMIS indicators and data collection instuments; and log-books, registries, reporting forms.

\section{Key informant interviews and observations}

Twenty-two key informant interviews were conducted. Informants were selected from the major health information sub-systems and programmes in $\mathrm{MoH}$ and key supporting partners at national and regional level. In addition, some managers of selective health facilities from all regions were interviewed. An open-ended questionaire was used for interviews in line with the contents of the HMN assessment tool used for group discussion and scoring.
The overall HMIS system and subsystems, resources and infrastracture, processes and outputs were closely observed throughout the research process. Sites observed included: national and regional HMIS offices, national and regional public hospitals, and selected PHCPrimary health care facilities in each region. Also, process of data collection, compilation, analysing, reporting and dissemination, data collection instruments, capacility and resource level were observed.

\section{Group discusions and scoring}

Entire HMIS components were assessed and scored in group discusions over 3 days. The group consisted of seven key informants from HMIS national and regional offices. The HMN assessment excel spreedsheet, version 4.00

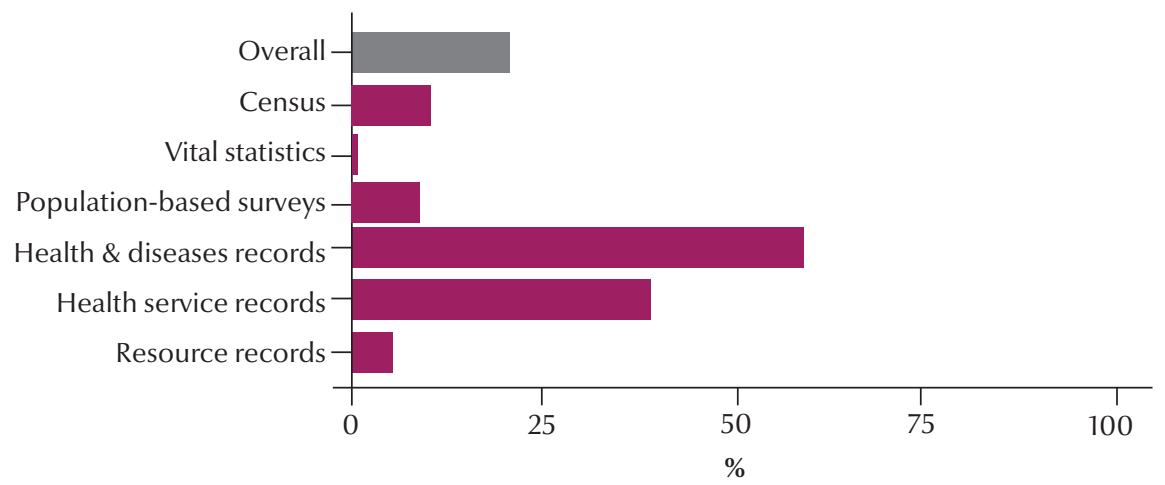

Figure 2 Par chart display of results of HMIS data sources 
(2008) was applied (16) where serial interlinked questions investigating each component of HMIS were presented to the group. Each indivitual was given an identifier code. Each participant gave a score with brief description, and an average score was subsequently taken. The exercise facilated to both quantify and qualitatively describe gaps in HMIS components assessed.

Data was analyzed using the "ready Excel spreadsheet", developed by WHO/HMN (17). For each item included in the assessment tool, a range of possible scenarios were provided from group discussion sessions to allow for objective and quantitative rating. The highest score (3) was given for a scenario considered "Highly adequate" compared to the gold standard as defined by the HMN Framework. The lowest score (0) was given when the situation is regarded as "Not adequate at all or "Not available". Two middle levels "Adequate" and "Present but not adequate" were given according to collective judgments (avarage scoring) of group members after discussion and reaching consensus. Total scores for each category were then aggregated and compared against the maximum possible score to yield a percentage rating.

Finally, the scores were conv erted into quartiles. Consequently, items with scores falling in the lowest quartile are classified as "Not adequate at all". Scores falling into the next lowest quartile are classified as "Present but not adequate", followed by "Adequate", and "Highly adequate" for those in the third and fourth quartiles respectively. Qualitative data obtained from key-informant interviews were categorized, along with the HMIS components and domains being assessed and complemented with findings from group discussion and scoring. Finally, primary and secondary data from various sources were converged with each to provide a comprehensive HMIS SWOT analayis.

An ethical clearance letter was issued from the $\mathrm{MoH}$ research committee. Written consent forms were distributed to respondents of both interviews and group discussions. No personal information was taken in interviews, observations or group discussions; an identifier code was used instead.

\section{Results}

Findings from the 22 key informant interviews, observations, group discussions and scoring conducted were merged and complemented to reflect the current status of HMIS as complete as possible. A comprehensive SWOT analysis of HMIS was carried out. Quantitative and qualitative findings related to each component of HMIS are listed, stressing the major gaps.

\section{Resources}

As Figure 1 indicates, HMIS resources, institutions, human resources, financing and infrastructure were levelled to an average of $43 \%$ (Present but not adequate). A functioning section of HMIS exists at central $\mathrm{MoH}$ office and six sub regional offices, but there were major gaps in HMIS, resources including: policy and strategy plan were not developed; no written standardized guidelines and procedures; poor ICT infrastructure and maintenance; full dependence on fragmented, unsuitable external technical and financial resources; and under-skilled and under-paid personnel at all levels.

\section{Health indicators}

Indicators were the highest scored component with an average score of $72 \%$ (adequate). Key health status indicators, particularly those related to donor supported program targets $t$ such as HIV/AIDs, TB, Malaria in line with the MDGs,Millennium development goals, are regularly measured and reported. The study explored a number of major gaps, namely: core health indicators were not selected according to standard criteria of $\mathrm{WHO}$ and no review done; measuring health indicators is based on estimates due to lack of actual information on population projections and denominators; data from the large private

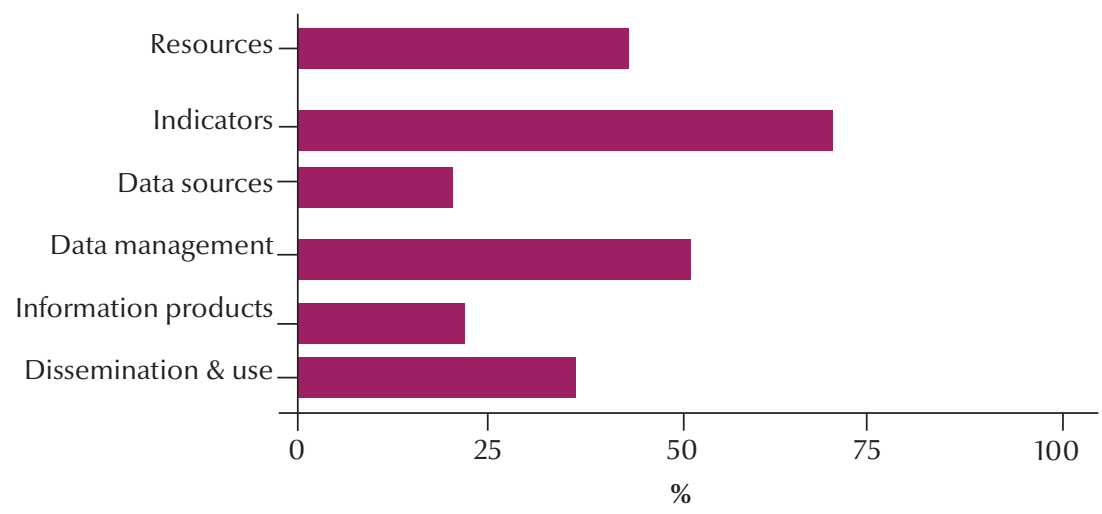

Figure 3 Par chart display of results of overall HMIS components 
health sector was not captured; different stakeholders and partners demanded different indicators, which resulted in large number of national core indicators that might be beyond the limited resource and capacity of HMIS; and locally important indicators were overlooked due to exceptional dependence on external funding focused on their own programme indicators.

\section{Data sources}

The overall score for data sources was $21 \%$ (Figure 2) (Not adequate at all). Health and disease records significantly scored higher than the rest, reaching an average of $60 \%$ (Adequate). This implies data captured by HMIS is mainly related to health status. The study found health resource data, which includes information on the density and distribution of health facilities, human resources for health, drugs and other core products and key health services, scored $40 \%$ (Present but not adequate).

The overall score of the census was 10\% (Not adequate at all). This was due to all core dimensions of census scoring close to $0 \%$ with the exception of capacity and practice availability, which scored 20\% (Not adequate at all). Thus, little capacity to collect, process and analyse census exists. Vital statistics system findings scored 5\% (not adequate at all). There is no nationwide vital statistics or civil registration or even sample registration system. Some unreliable and incomplete vital statistics are computed via health facilities records or population surveys; e.g. MICS 2011. Populationbased surveys scored 9\% (Not adequate at all) while a demographic surveillance system was not in place.

Other major gaps identified included: no national database/roster of public and private-sector health facilities or coding system for health facilities; no data obtained from the private sector; no research or surveys ( e.g. Public health expenditure track survey (PETS), , National health account (NHA) had been conducted to reveal financial information; (e.g. health expenditures, out-of-pocked payment or level and distribution of external aid); community-based health data were not captured; data fromupervisions for monitoring and evaluation were not organized, analyzed and integrated; health workers were not trained on ICD-10 for proper identification and registration of cases and deaths.

Data management scored 52\% (Adequate). The study found that despite no written set of data-management procedures for data management in place, HMIS staff at central and regional level do basic data management procedures in data collection, compilation, cleaning, quality controlling, storing, reporting, analysing and dissemination. Major gaps existing in this domain included poorly managed and fragmented data collection and reporting systems, and no effective database and warehouse at national or regional levels.

Information production scored an average of $22 \%$ (Not adequate at all) in general. . The assessment found that mortality indicators assessed were "Not adequate at all" while prevalence indicators reflected a good status (Adequate). No disaggregation or adjustment of such indicators was made. Also, health system indicators reflected a poor status (Present but not adequate). In terms of data analysis and evidence generation, there was poor capacity at all levels. The system was dependant on external technical support and data production was constrained by not having accurate denominators as well as not receiving data from the private health sector.

In terms of dissemination and use, five aspects related to information use: analysis and use of information, policy and advocacy, planning and priority setting, resource allocation, and action taking. Assessment indicated these to be all less than 50\% (Present but not adequate). The assessment also revealed data that information surveys and M\&E visits are not systematically and continuously analysed and utilized for spatial analysis, monitoring and evaluation of health system performance. In addition, information was not always produced for policy-makers and decision-makers in an understandable format. In summary, Somaliland HMIS assessment found the highest scored components were "indicators" and "data management" with scores of $72 \%$ and $52 \%$ respectively (Figure 3). Contrastingly, the lowest scored components were "data sources" (21\%) and "information production” (22\%).

\section{Discussion}

There is no specific policy, legislation or strategy for HMIS in Somaliland, apart from general policy guidelines and strategy directions outlined in the National Health Policy (NHP11) and Health Sector Strategic Plan (HSSP 20132016). Experience from other countries indicate that an evidence-informed HMIS policy and strategy should be developed to achieve substantial progress in HMIS development through effectively mobilizing of resources, coordinating of efforts, and aligning of interventions. Some countries have developed national committee or task forces comprising key HIS stakeholders in the health sector to improve leadership, coordination and harmonization of efforts. In the case of Ethiopia, the country does not have a regular system for monitoring the performance of HIS. Instead, the NationalAdvisory Committee (NAC) of the HMIS took the lead for coordinating HIS activities (18).

To improve HMIS performance, it is critical to clarify roles, responsibilities and mandates among $\mathrm{MoH}$ management arrangements, other government agencies, the private health sector and partners. This could be realized by effectively enforced HIS legislation and regulation (19).

It terms of human resources, at the national level there is a considerable 
skilled workforce. However, some core competencies such as epidemiology, biostatistics, demography or HIS specialisations are still lacking. At regional public hospitals, there is one person responsible for data collection and reporting to regional HMIS office. However, at primary health facilities (health centre and primary health units), there is no specific person responsible. Instead, facility team leader voluntarily reports to regional HMIS officer.

Despite HMIS suffering deficiencies in financial resources, it is supported by external partners. Such external funds are of limited impact if there is no policy and strategic plan to guide HIS strengthening efforts. One major financing problem of most developing countries is chronic dependence on external funding, which limits the ability of HMIS to produce locally relevant information useful for decision-makers and programme managers. In addition, sustainability of HMIS becomes critical once donor funding ceases (20). In the case of Somaliland, the system is paper-based; at national and regional level an excel programme is employed for data compilation and reporting via email. From district to facility level communication is done either by telephone or transporting hard copies of completed reporting forms. Information communications technology (ICT) has been implemented by developing countries for electronic records and databases; however, it remains largely unexploited due to relying on unsuitable external technical and financial support (21-23).

Health indicators were the highest scored component - indicating as "Adequate" - due mostly to the fact that such indicators, particularly those related to health status, receive greater attention and support from donors and partners compared to other HMIS components. A good example is those related to MDGs; maternal mortality rate, infant mortality rates, Malaria, TB, HIV/AIDS morbidity and mortality. Selection of national core indicators should be informed by evidence and sound criteria. However, for Somaliland, the selection was based on stakeholder consensus, with particular emphasis on information need for donor-driven vertical programmes. As a result, the current national list of indicators does not encompass all domains, whereby mainly health status and few health systems-related indicators are measured. Risk factor indicators are the least considered. More importantly, indicators are not clearly linked to HSSP.

In Somaliland, various development or implementing partners of health systems have introduced different indicators, reporting mechanisms and monitoring and evaluation tools. This in turn, increased the workload on frontline health workers (data collectors and reporters), thereby wasting the limited resources and capacity of HMIS. Preferably, the country should carefully define a minimum set of core health indicators that fit well with the HIS capacity level in place. Failure to do so could threaten the entire system. This was implicit in the case of Ethiopia where a total of 105 core indicators were identified to monitor and evaluate the health sector development plan (HSDP). Unfortunately, subsequence reviews showed that HMIS needed a lot of resources to measure all these indicators and could not be done properly. As result, indicators have been reduced as part of the ongoing Ethiopian HMIS reforms (18). Measuring core health indicators, in the case of The Kenyan HMIS, has been fragmented by different donor-driven programmes focusing more on their own indicators (24).

Data sources were found as "Not adequate at all”. Various surveillance strategies have been developed by vertical disease control programmes with no clear connection with HMIS central office. These programmes use WHO standard case definitions of key epidemic-prone diseases and diseases targeted for eradication and/or elimination.
At facility levels there is no retained patient medical recording system to support quality and continuity of care. Data collection tools used at $\mathrm{MCH}$ / Health centre level are eight registers and six registers at hospitals. There are a number of tally sheets or daily sheets that have been designed to summarize data from the individual registers. The capacity of health workers to diagnose and identify diseases at different facilities is limited.

There has been no comprehensive population and household census conducted in Somaliland for the last 30 years. There is no nationwide vital statistics or civil registration or even sample registration system. Incomplete vital statistics are computed from deaths and births registered in health facilities records, or occasionally estimated by population-based surveys (11). However, the ministry of health recently conducted with WHO support its first Maternal Mortality Study in the country using Standard Verbal autopsy. Similarly, a pilot civil registration project in two regions in the country has been conducted with no preliminary data realised yet. Meanwhile, no legal foundation for civil registration has been established so far. Evidence from various settings, particularly low and middle-income countries, indicates that civil registration is weak, or does not exist, and cannot serve as a good statistical source of vital (25). To improve this, there should be clear strategic objectives along with a legally enforced registration process for effective implementation (26).

Population surveys are the most important source of population health information in many developing countries. For example, out of the 23 health-related MDG indicators, 17 are generated through household surveys (27). In Somaliland, Demographic and health survey DHS have not been conducted so far. However, multi indicator cluster survey (MICS) was carried out in Somaliland in 2011. 
At the national level, there is a human resource excel spreadsheet dataset containing essential information of the public sector workforce. However, it does not provide statistics disaggregated by professional category or workforce indicators. There is no information about the private health sector workforce or annual numbers of graduating health professionals. Data related to public health expenditure for health services, equipment, supplies and commodities were not systematically collected. It has been recommended that such research evidence should be integrated into HIS (28).

To manage better the various fragmented data sources, as in the case of Somaliland, some countries have adopted an integration strategy. While some have managed to standardize and integrate vertical programmes into the national HIS, reviews of the workability of integration strategy in different countries have highlighted challenges including:

- contextual factors related to politics;

- institutional arrangements;

- resource constraints (poor infrastructure, limited low skill human resources and limited financial resources);

- heterogeneity of interests among donors, managers and health reformers; and

- multiplicity of reporting systems even within individual programmes $(10,11,29)$.

For example, in Ethiopia and Sudan it was reported that Integrated Disease Surveillance and Response (IDSR) records, which focused on 17 priority diseases, have been implemented. Nevertheless, none of these records were integrated into national HMIS $(9,18)$. Therefore, Sudan realized the importance of Integration strategy as a key solution for reducing the burden of data completion and reporting, as well as promoting effective and efficient data production and information utilization and dissemination (9).

Data management was "Adequate". HMIS regional and central offices crosscheck quality of health facility data by comparing the individual registers with the monthly report during supervision visits. However, data collected by HMIS generally remains of poor quality, and it widely accepted that this has adverse effects on policymaking and implementation of health programmes. In this context, Uganda has established a Data Quality Audit to improve data quality for effective decision-making. In addition, data collection tools and forms were recommended to be streamlined to reduce the burden and time that health workers spend on data collection and reporting, and consequently improve quality (23). Elsewhere, it has been found that the effective management of the HMIS is largely determined by the availability of trained and motivated staff at each level as well as effective reporting and feedback (14).

Regarding information production, the study showed that mortality indicators were not adequate at all. This might be attributed to the limited data available on vital statistics in situations where civil registration or sample registration do not exist. Mortality data is poorly captured through health facilities registries. However, prevalence indicators are estimated and shown to be in a relatively good status. No disaggregation or adjustment of such indicators were observed.

National HMIS data analysis is done primarily via the analytical and graphic functions of Microsoft Excel, yet human skills and computer software were severely limited. For example, there was no biostatistician or epidemiologist experts at regional and national HMIS offices. It was observed that the technical part of measuring key health indicators is mainly done by supporting and implementing agencies. As result, some contradicting information was reported.

Information dissemination and use was found to be present but not adequate. HMIS was used to produce annual reports, and yet there were no reports in 2013 and 2014. There is mobile-based "good morning" surveillance bulletin, which reports notifiable diseases and other related health events to $\mathrm{MoH}$ directors and disease programme managers on daily basis. In addition, there are various annual reports produced by partners; for example, UNICEF produces an "HMIS Yearly Report" for all Somalia. However, its value is limited by the absence of up-to-date population data necessary for measuring accurate morbidity and mortality indicators. Therefore, the report is of little use for Somaliland $\mathrm{MoH}$ when monitoring health systems performance or even for making decisions at programme level.

The information displayed in HMIS reports are not usually appropriately interpreted and presented in a manner that can facilitate an evidence-based decision-making process. To increase information uptake, there should be a promotion of a culture of evidencebased decision-making. In terms of regional evidence, a paper from Kenya proposes a systematic intervention with a wide range of actions including technical, individual, and organizational aspects to promote a culture of information usage (30). Information should be presented in a way that links data/ information to actual resource allocation (budgets) and develops indicatordriven planning in order to increase information utilization (23,31). Good feedback is also one of the key solutions to improve overall HIS performance and data usage and dissemination in particular. Poor feedback can have a negative impact on health workers' motivation to take part in reporting processes, and as a result reduce availability and quality of health information (5). 
Recommendations to bridge major HMIS gaps

Despite the fact that current HMIS is striving to function under severely limited resources and capacity, some aspects of HMIS were found to function reasonably. The study has identified many gaps, almost in all components, of Somaliland HMIS. However, more light is shed on major gaps to draw evidencebased recommendations to develop the next HIS strategy plan (2015-2020). In short, the study makes recommendation to the $\mathrm{MoH}$ and other concerned development and implementing partners to develop a harmonized HMIS strategic plan that would serve as an effective tool of advocacy for HIS; mobilize sustainable financial and technical support; improve inter-sectoral collaboration; and more importantly would align fragmented systems and resources to more effective and efficient way. The following area of interventions are to be considered while developing the national HIS/HMIS strategic plan:

- Formulate a national HIS committee of key relevant stakeholders to lead, coordinate, mobilize and align different resources, oversee and guide HIS strengthening strategies.

- Develop, disseminate and implement an enforced national HIS policy to guide and advocate for a "more integrated HIS", improve institutional and human capacity, and to define clearly mandates and responsibilities.

- Review and map all fragmented financial and other resources, from any source, for any aspect of HMIS, M\&E systems, vital registration system, communicable disease surveillance, and vertical diseases surveillance systems. Such critical information could inform better the following important strategic decisions:

- o Harmonize available resources to minimize duplications and waste, thus foster HIS integration and strengthening efforts,

- o Identify and scale up resourceconstrained, least developed components of HIS and related sub-systems,

- o Ensure an adequate and sustainable fund from the governmental $(\mathrm{MoH})$ budget and development partners.

- Conduct HIS staff training needs assessment to develop a competencebased training curriculum addressing the following core HIS competencies: information management technology, biostatistics, epidemiology, computer sciences and bio informatics, among others.

- Invest in more harmonized HIS infrastructure, primarily data collection and reporting tools, patient records, civil registries, data analysis software, national information database and basic communication networks.

- HIS committee should initiate and lead reviewing the current fragmented health indicators to set evidence-based minimum core health indicators that do not overburden the health systems. To do so, the following guiding principles should be taken into account:

- Consider evidence and standard criteria for selection process (e.g., WHO Guidelines and criteria for core health indicators),

- o Balance between selecting national and international required indicators,

- Select indicators from all categories (determinants of health, health system inputs, outputs, outcomes and health status including SDGs related targets) as much as possible and link it with the country's HSSP to monitor and evaluate health systems performance at all levels.

- Close the gap in availability, access, quality and utilization of health in- formation by acting on the following areas of intervention:

- Review and validate estimated population projection "denominators" to measure core health indicators (e.g.; mortality and morbidity rates);

- introduce public-private partnership initiatives to facilitate establishment of a cost-effective system that captures data from the private health sector;

- conduct public health facility assessment (SARA) and mapping to capture aspects of resource information;

- set up a mobile community-based information system to scale up collection of health data;

- conduct a DHS survey, household health expenditure survey and national health account to close the substantial gap existing in availability of information related to population demographics, social determinants of health, and risk factors, as well as financial information, including out-ofpocket payment;

- produce and disseminate information in appropriate formats for different target audiences;

- create and promote information sharing and utilizing culture to link information and evidence to policy formulation, resource allocation and advocacy at different levels of health care;

- strengthen feedback communication, particularly to frontline health workers to enhance their motivation and work commitment;

- develop and disseminate explicit standardized guidelines and procedures for integrated management of data processing including collection, storage, cleaning, quality assurance, protection, analysis and presentation; and 
- establish an integrated national electronic data depository within the National HMIS section, containing data from all sub-systems, including malaria, HIV/AIDs, and $\mathrm{TB}$, which can be openly accessed by all concerned information users.

\section{Limitations}

The study is limited by a severe lack of previous research, documents, or literature concerning Somaliland HMIS. Furthermore, poor information sharing among various partners has restricted any secondary data collection process. The study attempted to explore clear in-depth contextualization of the current HMIS and other sub-information systems. However, this was not completely achieved due to the existence of many vertical programmes with no clear coordination or feedback.

\section{Funding: None.}

Competing interests: None declared.

\section{References}

1. Lippeveld T, Sauerborn R, Bodart C. Design and implementation of health information systems. Geneva: World Health Organization; 2000 (http://rhinonet.org/files/2013/06/ hmis_chapter10_resources.pdf).

2. Abou Zahr C, Boerma T. Health information systems: the foundations of public health. Bull World Health Organ. 2005 Aug;83(8):578-83. PMID:16184276

3. World Health Organization. Everyone's business: strengthening health systems to improve health outcomes: WHO's framework for action. Geneva: World Health Organization; 2007.

4. Carraro L, Khan S, Hunt S, Rawle G, Robinson M, Antoninis M et al. Monitoring the millennium development goals: current weaknesses and possible improvements. Glasgow: Oxford Policy Management, Department for International Development; 2004.

5. World Health Organization. Country health information systems; a review of the current situation and trends. Geneva: World Health Organization; 2011 (http://www.who.int/ healthinfo/country_monitoring_evaluation/documentation/ en/).

6. Luna D, Almerares A, Mayan JC, Gonzalez F, de Quiros B, Otero C. Health informatics in developing countries: going beyond pilot practices to sustainable implementations: a review of the current challenges. Health Inform Res. 2014 January; 20(1):3-10 (http://dx.doi.org/10.4258/hir.2014.20.1.3).

7. Odhiambo-Otieno GW. Evaluation of existing district health management information systems a case study of the district health systems in Kenya. Int J Med Inform. 2005 Sep;74(9):73344. PMID:15979937

8. Kamadjeu RM, Tapang EM, Moluh RN. Designing and implementing an electronic health record system in primary care practice in sub-Saharan Africa: a case study from Cameroon. Inform Prim Care. 2005;13(3):179-86. PMID:16259857

9. World Health Organization. Sudan Health information system; review and assessment. Geneva: World Health Organization; 2007 (http://www.who.int/healthinfo/country_monitoring_evaluation/documentation/en/).

10. Chilundo B. Integrating information systems of disease-specific health program in low income countries: the case study of Mozambique. Ph.D. thesis, University of Oslo, 2004.

11. Nyell E. Challenges in health information systems integration: Zanzibar experience. J Health Inform Dev Ctries. 2011 (https://pdfs.semanticscholar.org/74cd/c93732f89a5a5dc2cb6235323eac3a4215ae.pdf).

12. UNICEF. Health system; strengthening for Somali people: a workshop report 1. Geneva: UNICEF; 2007 (https://www. unicef.org/somalia/SOM_resources_hss.pdf).

13. Somaliland HMIS. Annual health report 2006 (unpublished).
14. Daniels M. National HMIS rapid Assessment 2013 (unpublished).

15. World Health Organization. Framework and standards for country health information system, second edition. Geneva: World Health Organization; 2008 (http://apps.who.int/iris/ bitstream/10665/43872/1/9789241595940_eng.pdf).

16. World Health Organization. Assessing nation health information system: an assessment tool version 4.00. Geneva: World Health Organization; 2008 (http://apps.who.int/iris/bitstre am/10665/43932/1/9789241547512_eng.pdf).

17. WHO. (health metrics network), assessing national health information systems; Excel spreadsheet, version 4.00, 2008 available at http://www.minsa.gob.pe/ogei/conferenciaops/ Recursos/13.pdf

18. World Health Organization. Assessment of the Ethiopian national health Information system report. Geneva: World Health Organization; 2007 (http://www.who.int/healthinfo/ country_monitoring_evaluation/documentation/en/).

19. Gordon AN, Hinson RE. Towards a sustainable framework for computer based health information systems (CHIS) for least developed countries (LDCs). Int J Health Care Qual Assur. 2007;20(6):532-44. PMID:18030970

20. Heeks R. Information systems and developing countries: failure, success and local improvisations. Inf Soc. 2002;18(2):10112.

21. Sahay S, Avgerou C. Introducing the special issue on information and communication technologies in developing countries. Inf Soc. 2002;18(2):73-6.

22. Braa J, Hedberg C. The struggle for district-based health information systems in South Africa. Inf Soc. 2002;18(2):113-27.

23. Kintu $P$, Nanyunja M, Nzananita A, Magoola R, Axios Group, WHO country office for Uganda, et al. Development of HMIS in poor countries: Uganda as a case study. Health Policy and Development. 2005;3(1):46-53.

24. WHO (HMN). Kenyan health information system; review and assessment, 2008 accessed online at https://healthresearchweb.org/?action=download\&file=HISAssessmentfinalrepo rt23.09.08.doc

25. Mathers CD, Fat DM, Inoue M, Rao C, Lopez AD. Counting the dead and what they died from: an assessment of the global status of cause of death data. Bull World Health Organ. 2005 Mar;83(3):171-7. PMID:15798840

26. United Nations Statistics Division. Principles and recommendations for a vital statistics system (revision 2 series). New York: United Nations; 1998 (https://unstats.un.org/unsd/publication/SeriesM/SeriesM_19rev2E.pdf).

27. United Nations Statistics Division. Household sample surveys in developing and transition countries series: F, no.96. New 
York: United Nations; 2005 (https://unstats.un.org/unsd/ hhsurveys/pdf/Household_surveys.pdf).

28. Krickeberg K. Principles of health information systems in developing countries. Health Inf Manag. 2007;36(3):8-20.

29. Galimoto M. Integration of health information systems: case study from Malawi. Master thesis, University of Oslo 11 May, 2007 (https://www.duo.uio.no/bitstream/handle/10852/9772/Galimoto.pdf?sequence=1\&isAllowed=y).
30. Hahn D, Wanjala P, Marx M. Where is information quality lost at clinical level? A mixed-method study on information systems and data quality in three urban Kenyan ANC clinics. Glob Health Action 2013;6:21424 (http://www.tandfonline.com/ doi/full/10.3402/gha.v6i0.21424).

31. Health information systems in developing countries: a landscape analysis. Vital Wave Consulting May 2009 (http://www. minsa.gob.pe/ogei/conferenciaops/Recursos/43.pdf). 